\title{
Un aspecto de la literatura testimonial del siglo XVIII español: El bosquejillo de José Mor de Fuentes
}

\author{
Luigi Contadini \\ Universidad de Bolonia
}

Resumen

Este trabajo pone de relieve tres puntos fundamentales de la autobiografía de Mor de Fuentes: 1) El desarrollo de la conciencia del autor como individuo a través de una visión intelectualista de la vida (que encuentra en el espacio urbano su medio ambiente específico) y su identificación con los juicios y las ideas que sostiene. 2) La tensión incesante entre el saber oficial y el discurso personal de autobiógrafo. La superposición asidua del discurso subjetivo sobre el discurso historiográfico acaba por deformar la verdad establecida. El narrador diluye su identidad en un sinfín de acontecimientos y juicios: historia oficial e historia personal se confunden continuamente en una narración que borra los límites entre la visión pública de los eventos y la itnerpretación particular del protagonista. 3) La simultanediad del relato que desplaza la atención del lector hacia el tiempo presente de la redacción y pone de relieve las exigencias del autpr en el momento de la escritura.

Frente a una sociedad en la que nunca tuvo un verdadero y constante éxito, Mor obtiene una revancha moral escribiendo una autobiografía porque tiene la necesidad de reescribir la historia para que se convierta en su historia.

José Mor de Fuentes (1762-1848, natural de Monzón) escribe el Bosqueji$l l o^{1}$ principalmente para rescatar su obra literaria y su vida de intelectual ilus- 
trado del olvido en el que la comunidad cultural europea las había relegado, y para conseguir un reconocimiento que hasta aquel momento nunca había tenido ${ }^{2}$. La vida del escritor abarca un período fundamental para la historia de España, lleno de transformaciones ideológicas y culturales, de guerras y cambios políticos. Él, sin embargo, manifiesta en toda la vida su formación dieciochesca, declarándose escritor y poeta, hombre de ciencia y patriota. Su actividad encaja perfectamente con la entusiasta creencia, ya mencionada por Luzán, en la perfectibilidad del hombre mediante el progreso científico, artístico y literario, incluso en el terreno filosófico y educativo ${ }^{3}$.

El Bosquejillo es una autobiografía ${ }^{4}$ breve y apretada pese a la densidad de los hechos evocados, escrita de una manera fragmentaria, violando la cronología y provocando a menudo el efecto de la simultaneidad temporal. El autor omite años enteros de su existencia y se detiene abundantemente sobre algunos temas predilectos: la producción literaria y la capacidad de poeta políglota, la participación en la Guerra de la Independencia y la actividad de periodista,

${ }^{1}$ J. Mor de Fuentes, Bosquejillo de la vida y escritos de José Mor de Fuentes (M. Alvar ed.), Zaragoza, Guara, 1981. Las restantes citas de la obra se refieren a esta edición. El Bosquejillo fue publicado por primera vez en 1836, en Barcelona, por el editor Bergnes.

${ }^{2}$ Azorín fue el primero en rescatar la figura olvidada de Mor de Fuentes, sobre todo por su prosa viva y despejada, con frases cortas y directas, muy alejada del estilo desmañado y retórico a que el lector de la época estaba acostumbrado: «Mor de Fuentes hace dar en su autobiografía y en su novela La Serafina un gran paso a la prosa castellana. Su estilo no es el lento desvaído, uniforme, generalmente empleado por sus coetáneos; en estas páginas del Bosquejillo aparece ya la prosa viva, enérgica, real, plástica, pintoresca, que más tarde había de desenvolverse bajo la pluma de escritores más cercanos a nosotros» (Azorín, «Mor de Fuentes», en Lecturas españolas, Madrid, Espasa Calpe, 1957, pág. 82). Arco confirma el juicio de Azorín: «Mor de Fuentes marca en sus obras un progreso evidente en la prosa castellana: su estilo es recortado, enérgico, claro» (R. del Arco y Garay, «Independencia. José Mor de Fuentes», en Figuras aragonesas (El genio y la raza), Zaragoza, Tip. Heraldo de Aragón, 1923, núm. 1, págs. 153-154). También Gimferrer expresa una opinión parecida: «La prosa española moderna respira aquí con claridad y sin ahogos» (P. GIMFERRER, «Mor de Fuentes, un transeúnte», en Los raros, Barcelona, Planeta, 1985, pág. 147).

${ }^{3}$ R. P. Sebold, «Prólogo» a I. de Luzán, La Poética, Labor, Barcelona, 1977, pág. 22.

${ }^{4} \mathrm{El}$ pacto de que habla Lejeune, que supone la aceptación por parte del lector de la misma identidad entre autor, narrador y protagonista, es asumido por el mismo título de la obra y renovado implícitamente a través de la sección inicial del texto en la que el narrador se compromete con el lector a comportarse como si fuera el autor («voy a rasguear, compendiosa e imparcialmente, mi biografía, tanto por la carrera militar como por la literaria. Soy natural de Monzón», pág. 43) y de manera patente, al nivel del nombre que se da el narrador-personaje en la narración, y que coincide con el del autor en la portada (P. LEJEunE, «El pacto autobiográfico", en Anthropos suplementos. La autobiografía y sus problemas teóricos, núm. 29, 1991, págs. 48, 53). Sin embargo, ello permite reconocer el género literario, pero no soluciona el problema de la identidad: «El nombre en la página del título no es el nombre propio de un sujeto capaz de autoconocimiento y entendimiento, sino la firma que da al contrato autoridad legal, aunque no le da en absoluto autoridad epistemológica» (P. DE MAN, «La autobiografía como desfiguración», en Anthropos Suplementos. La autobiografía y sus problemas teóricos, núm. 29, 1991, pág. 114). Además, Demetrio opina que a través de la autobiografía la unidad ideal entre autor, narrador y protagonista se dispersa porque prevalece la búsqueda espontánea de la disociación entre estas tres figuras. Escribiendo sobre sí mismo se da vida a un personaje otro (D. Demetrio, Raccontarsi. L'autobiografía come cura di sé, Milano, Cortina, 1996, pág. 55). 
la fidelidad a los principios liberales e ilustrados y el relato de su estancia en París, donde intenta entrar a formar parte de su prestigiosa comunidad científica y literaria. Su compromiso constante está orientado principalmente en dos direcciones: expresar opiniones personales emitiendo juicios y, al mismo tiempo, establecer una coincidencia entre su carrera militar y literaria, y los acontecimientos militares y literarios de España.

La obra manifiesta una tensión incesante entre el saber oficial y los eventos que ya han recibido un estatuto histórico, y el discurso personal del autornarrador. El resultado es un tipo de relato en que la superposición asidua del discurso subjetivo sobre el discurso historiográfico deforma la verdad establecida.

El narrador diluye su identidad en un sinfín de acontecimientos y juicios: historia oficial e historia personal (saber oficial y opiniones personales) se confunden continuamente en una narración que borra los límites entre la visión pública de los eventos y la interpretación particular del protagonista.

\section{Las opiniones}

Mor pertenece a un numeroso grupo de personajes de la generación anterior a la que realizó la primera revolución liberal, y por lo tanto de inspiración, cultura y formación ilustrada, pero que escriben sus memorias en medio de un ambiente ya liberal y romántico $0^{5}$. Las obras autobiográficas de este tiempo tienen en común el carácter de memorias justificativas, de crónicas autoapologéticas que persiguen la rehabilitación ante la opinión pública del honor dañado o no reconocido de sus autores. Lo que suscita el interés de los lectores modernos es el afán de explicarse tomando como punto de arranque la confianza en el propio gusto literario y artístico, en la curiosidad ante todos los campos de la cultura, el arte o las ciencias, en las opiniones sobre temas eruditos o filosóficos ${ }^{6}$. Tales autores, intelectuales ilustrados, y de cultura clásica, «identifican sus personalidades con los argumentos que aportan y las ideas que sostienen» ${ }^{7}$.

Las autobiografías de esta época se escriben para recuperar una fama, que ha sido puesta en entredicho mediante acusaciones más o menos formales, elevando un recurso ante la instancia más transcendente de la historia, la nación

\footnotetext{
${ }^{5}$ F. Durán López, «Autobiografía, espacio urbano e identidad del intelectual ilustrado: el caso Mor de Fuentes», en Cuadernos de Ilustración y Romanticismo, núm. 3, 1993, págs. 76-77.

${ }^{6}$ Ibíd., pág. 79.

${ }^{7}$ F. Sánchez Blanco, «Autobiografía y concepción del yo desde Mor de Fuentes a Ramón y Cajal», en Revista Canadiense de Estudios Hispánicos, XI, núm. 3, 1987, pág. 635.
} 
o la opinión pública ${ }^{8}$. Lo que constituye la obsesión de Mor es la adquisición de la fama por una cualidad (la de hombre ilustrado experto tanto en el ámbito científico como en el literario) nunca reconocida públicamente, cualidad que se convierte en identidad privilegiada. Su recurso está dirigido por lo tanto a la historia de la cultura europea de la cual pretende un reconocimiento oficial.

El sujeto capaz de expresar su inteligencia es uno de los temas que se pone en primer plano en el Bosquejillo: el autor se considera ante todo como una inteligencia polifacética producto de una formación humanista e ilustrada. $\mathrm{Su}$ vida traza el arquetipo de hombre igualmente formado en las humanidades clásicas y en las nuevas disciplinas técnicas. La autobiografía se convierte, por lo tanto, en una especie de conjunto de opiniones sobre una gran variedad de asuntos de la vida de aquella época. Con ella intenta precisar y comentar las diversas situaciones en las que se ha encontrado como hombre público. Su obra se confunde con un formulario de juicios y definiciones que a menudo sobresalen con respecto a la narración (nunca larga y detallada) de un acontecimiento, mientras es muy poco el espacio que el autor dedica a su vida privada, sus relaciones amorosas y sentimentales ${ }^{9}$.

La expresión de opiniones personales sobre todo lo que es público surte el efecto de rebajar la verdad oficial, que Mor intenta sustituir con su propia «verdad», pidiendo que sea públicamente reconocida. El «yo», ya desde las primeras páginas, se confunde con el punto de vista conceptual del narrador que se superpone al personaje (a través de la utilización frecuente del tiempo verbal presente) y domina la escena de la obra ${ }^{10}$. Sus ideas, no sólo literarias o militares, abarcan todo tipo de materias, per ejemplo, asuntos de carácter científico: «como luego manifesté al Gobierno, y acogió mis razones, el agua dulce es nociva para la madera de pino, como lo tiene demostrado el célebre Duhamell» (pág. 47); las obras de fontanería en España: «¿Es posible, exclamé, en una nación donde tantísimo se ha escrito de teología inapelable, de jurisprudencia bárbara, de medicina irracional, de novelones chapuceros y de poesía insulsísima, nadie haya saludado un arte tan importante como el de la fontanería?» (pág. 49); la instrucción: «Se empeñaron mis deudos y allegados en que había de ir a helarme por la lobreguez de la tristísima y barbarísima Universidad de Zaragoza, a decorar a viva fuerza las irracionalidades de la rancia filosofía peripa-

\footnotetext{
${ }^{8}$ Ibíd., pág. 634.

${ }^{9}$ Como afirma Cáseda, refiriéndose no sólo al Bosquejillo, sino a toda su producción literaria, «[Mor] nunca se refiere a Dios, y rehuye deliberadamente todo asunto teológico o divino. Incluso entre sus contemporáneos resulta difícil encontrar un caso parecido» (J. CÁseda, Vida y obra de José Mor de Fuentes, Monzón - Huesca, Centro de Estudios de la Historia de Monzón - CEHIMO, 1994, pág. 109).

${ }^{10}$ Véase: S. Chatman, Story and Discourse: Narrative Structure in Fiction and Film, Ithaca - London, Cornell University Press, 1978.
} 
tética» (pág. 44); la literatura: «Meléndez ha sido para mí [...] el verdadero y casi único Poeta castellano, mirando con mortal desabrimiento nuestros dieciseisenos y demás campeones del Parnaso español» (pág. 45); estrategia militar y política: «me afirmo nuevamente en que fue muy acertado el conato de la Junta del Gobierno y del Consejo Supremo en contener al pueblo y hacer que cesasen las hostilidades, pues sin esta providencia es innegable que Madrid hubiera sido inundado en sangre» (pág. 64) ${ }^{11}$. En París, con una curiosidad vital, intenta explicarse la razón de todo lo que ve:

fructifican asombrosamente las ciencias [...] disfruté allí la música más original y peregrina que jamás he oído, pero conceptué que faltaba fuerza de instrumentos para el cabal complemento de la melodía [...] Osténtase el magnífico Louvre [...] formado de cuerpos tan diversos que carece absolutamente de unidad $[\ldots]$ los franceses [...] propenden infinito a realzar sus distintos u objetos con dictados campanudos $[\ldots]$ en el interior de las casas suele reinar extremado aseo [...] el establecimiento ventajosísimo es el de los carruajes llamados ómnibus (págs. 100, 104, 109, 114, 118).

Mor dicta sentencias también sobre sus colegas literatos y sobre la situación de las letras en España, en Europa y más tarde en Francia, llegando a negar, por su radical antirromanticismo, el valor literario de Hugo, Scribe, etc. Así como había negado importancia a Moratín («sus comedias para mí carecen absolutamente de imaginación», pág. 59), tampoco reconoce el mérito de Quintana y de Gallego («la altisonante jerigonza alternada con renglones rastreros de Quintana o de Nicasio Galleguísimo», pág. 114), del Duque de Rivas («que nos ha traído un comedión [...] sacado de las íntimas entrañas de la nueva antiescuela parisiense», pág. 114) y de Martínez de la Rosa («el yerto prosaísmo del chusco Martínez», pág. 114). Mor se burla de todos los románticos franceses y de los europeos en general:

Los anovelados, o, como dicen bárbaramente, «románticos», ya que blasonan de escrupulosísimos «naturalistas», no tienen más que ostentar en el centro de sus augustas decoraciones una magnífica letrina y allí disfrutar las correspondientes operaciones, que por desgracia son todas naturalísimas (pág. 99)12.

\footnotetext{
${ }^{11}$ A este respecto Cáseda subraya que la observación de Mor (sobre la rebelión de los españoles en los primeros días de mayo), que aparece repetida en varios escritos suyos, es muy poco común entre sus contemporáneos (Cáseda, Vida y obra de José Mor de Fuentes, pág. 237).

12 Por lo que se refiere a la polémica contra el Romanticismo, Azorín soluciona la aparente contradicción entre el espíritu rebelde e individualista del autor y su rechazo de la corriente romántica que ya se iba
} 
No reconoce a ningún maestro, excepto a Meléndez Valdés, aunque no explica la razón de esta preferencia, y afirma su independencia de todos ${ }^{13}$. Por lo tanto, no hay que considerar sus juicios negativos como consecuencia de rivalidad, rencor o envidia, sino como ulterior manifestación de su personalidad que supone una necesidad de revancha y de conseguir un sitio en el ámbito de las letras europeas.

Otros ejemplos importantes se refieren a los acontecimientos de la Guerra de la Independencia. Es revelador que Mor afirme, con respecto a los hechos de la invasión francesa de 1808: «En esto yo me hallaba sumamente comprometido por una sátira contra Godoy y contra el mismo Bonaparte» (pág. 64). Su compromiso, por lo tanto, procede de una actividad literaria y evidencia la importancia que otorga a su capacidad de escritor. El hallarse «sumamente comprometido» supone también la identificación del sujeto con su propio valor literario y capacidad intelectual tales como para pensar que sus escritos pudieran estar leídos y discutidos por un público amplio ${ }^{14}$. En el relato de las varias actividades que Mor desarrolla durante la Guerra de la Independencia destaca la composición de una notable cantidad de escritos político-militares:

además de varios papelillos que solía insertar en el Diario, publiqué unas Reflexiones sobre el estado de la nación, que se enviaron a Cádiz y merecieron aprecio; luego un folleto intitulado Las Cortes y la Regencia [...] en seguida, otro al mismo intento, El Ingenuo; luego en Murcia Los nuevos desengaños [...] uno absolutamente militar, con el título de Elementos de táctica superior. Había antes dado a luz un poemita sobre la libertad de la imprenta, que acababan de sancionar las Cortes, acompañado de notas (pág. 73).

Si la expresión de opiniones pone de relieve al narrador con respecto al protagonista, en estos fragmentos el «yo» del protagonista, mostrándose como escri-

afirmando: «Mor de Fuentes, contrariamente a lo que podría suponerse, dado su carácter libre, independiente, profundamente individualista, detestaba el romanticismo. La explicación del fenómeno, de la contradicción, debe verse en este carácter de realismo, de naturalismo violento, de imitación de la realidad, que la escuela romántica afectó en sus primeros tiempos, como reacción — reacción un tanto brutal— en contra de la rigidez, de la uniformidad, de la idealización del clasicismo» (Azorín, «Mor de Fuentes», pág. 77).

${ }^{13}$ Sin embargo Cáseda pone de relieve que las razones de la afición de Mor con respecto a Meléndez proceden del prestigio y del magisterio que éste ejercía en el ámbito de la mayoría de los poetas de aquella época y que ni siquiera el mismo Mor pudo evitar. El aspecto más significativo que el escritor aragonés hereda de Meléndez es el autobiografismo de sus composiciones poéticas. El mismo estudioso afirma que «El primer poema del libro impreso en su carrera, se titula «De la poesía» y está dedicado a su «amigo» Juan Meléndez Valdés. La idea de «guía» se repite en él, así como una definición del objeto de la poesía» (Cáseda, Vida y obra de José Mor de Fuentes, pág. 91).

${ }^{14}$ Mor menciona a menudo sus publicaciones y en varias ocasiones se cita a sí mismo revelando la importancia de su papel de literato: «véanse en La Serafina algunas alusiones a estos sitios y pasatiempos» (pág. 48). 
tor, remite a sí mismo en cuanto «autor» de varios textos literarios. La autobiografía, si por una parte alude a la posible unidad entre las tres figuras de las cuales habla Lejeune, por otra no deja de desvelar sus diferencias ${ }^{15}$.

La importancia del aspecto intelectual se revela también a través de la identificación del narrador-protagonista con un cierto tipo de ambiente. Mor dedica casi la mitad de su Bosquejillo a la descripción de su estancia en París, no obstante la edad avanzada al realizar el viaje (71 años) y la corta duración de la misma (cuatro meses). Este relato le permite reconocerse en la capital cultural de Europa, que se convierte en lugar propicio para exhibir su condición de poeta políglota e intelectual curioso por cualquier acontecimiento público ${ }^{16}$. El caso de Mor es ejemplar: por una u otra razón tuvo que permanecer largos periodos alejado del ambiente urbano y cultivado en el que deseaba vivir. Hay fragmentos del Bosquejillo en los que se queja de su situación, añorando el movimiento y las posibilidades del ambiente ciudadano: «Reempozado en mi secatura monzonera [se refiere a Monzón, su pueblo natal], como solía yo llamarla» (pág. 84). La demostración de la clara conciencia de que la ciudad es su lugar natural se manifiesta en la descripción de su viaje a París. La capital francesa representa un suceso verdaderamente importante en su vida: «Llegó por fin el punto de emprender mi anhelado, y no sé si diga memorable, viaje a París, que es forzoso referir con alguna extensión» (págs. 85-86). En las descripciones existe una marcadísima hegemonía del espacio urbano más desarrollado y civilizado, el que presenta la mayor riqueza intelectual y trato social: el sujeto se identifica casi totalmente con lo que observa y experimenta ${ }^{17}$.

La estancia en París le sirve a Mor también para averiguar el valor de su producción poética ${ }^{18}$, dado por descontado que, siendo Francia un país modelo por cultura y desarrollo científico, el reconocimiento intelectual de un español en Francia era, por lo tanto, el más elevado a que un hombre de letras podía aspirar $^{19}$. Con un pie en el Antiguo Régimen y otro en el mundo moderno desarro-

\footnotetext{
${ }^{15}$ Véase la nota núm. 4.

16 «El espacio en el que el intelectual vive, y por el cual se define, es el espacio urbano; y no simplemente la ciudad como núcleo de poder o como aglomeración humana, sino muy simplemente la ciudad concebida como centro cultural, como depositaria de los tesoros del saber y como lugar de reunión y de trabajo de los hombres sabios, sus iguales» (Durán LópEz, «Autobiografía, espacio urbano», pág. 80).

${ }^{17}$ El que Mor, paradójicamente, parezca olvidarse de sí mismo para dedicarse a la descripción del paisaje urbano, se justifica «con la filosofía de Condillac y Locke, según la cual la vida anímica consiste fundamentalmente en impresiones de los sentidos» (Sánchez Blanco, «Autobiografía y concepción del yo", págs. 636-637).

${ }^{18}$ Son muchos los episodios parisienses en los cuales Mor improvisa, como repentista, poesías en varios idiomas para sus interlocutores.

19 «su propia definición como individuo, nucleada en torno a su valía intelectual, queda, pues, perfilada a través de sus éxitos en Francia» (Durán LópEz, «Autobiografía, espacio urbano», pág. 85).
} 
lla su conciencia como individuo a través de una visión intelectualista de la vida, que encuentra en el espacio urbano su medio ambiente específico ${ }^{20}$.

El protagonista-narrador aparece como el verdadero hombre ilustrado que constituye la síntesis del saber humano: sabe de literatura como de ingeniería, de costumbres y de arquitectura, de estrategia militar y de política. Se identifica con sus opiniones conviertiéndolas a menudo en universales a través de sujetos impersonales o colectivos y utilizando con frecuencia el tiempo verbal presente. De esta manera desplaza la atención hacia la enunciación, acentuando el presente de la escritura ${ }^{21}$. La acumulación heterogénea de juicios superficiales y sin coherencia temática da a entender que el escritor «quiere decir más de lo que dice» ${ }^{22}$. En efecto, tales enunciados, además de servir para defender ideas, difundir opiniones o polemizar contra posibles detractores, tienen la finalidad primaria de manifestar la existencia de su emisor y afirmar su propia subjetividad. De esta manera Mor realiza la necesidad de ser individuo intelectualmente capaz y de estar en la comunidad cultural del tiempo: declarando lo que opina, anuncia al mundo su propia existencia ${ }^{23}$.

\section{Las coincidencias}

La Guerra de la Independencia provocó en los intelectuales una sacudida violenta, una necesidad de elegir. La política napoleónica en España modificó los sentimientos de Mor con respecto a Francia. El poeta aragonés se declara liberal y toma partido, con mucha pasión, por la lucha en contra de los franceses. No es raro que varias páginas del Bosquejillo sean dedicadas a los acontecimientos de la Guerra de la Independencia. La situación histórica origina una nueva y amplia actividad autobiográfica en las letras españolas en el momento en que se rompe la unidad política y espiritual y la sociedad se divide en «patriotas» y «afrancesados» y más tarde en partidarios de un poder absoluto o limitado por una Constitución. A menudo se hace necesario

\footnotetext{
${ }^{20}$ Ibíd., pág. 88.

${ }^{21}$ El tiempo verbal presente es un indicador autoreferencial que explicita el presente inherente a la eunciación (È. Benveniste, «L'appareil formel de l'énonciation», en Problèmes de linguistique générale II, Paris, Gallimard, 1974, págs. 83-84).

${ }^{22}$ El significado de la intención ilocutiva y el significado literal de la frase no coinciden (J. R. SEarLe, «Indirect Speech Acts», en P. Cole y J. L. Morgan (eds.), Syntax and Semantics. Speech Acts, New York London, Academic Press, 1975, pág. 59).

23 «Dans son tour syntaxique comme dans son intonation, l'assertion vise à communiquer une certitude, elle est la manifestation la plus commune de la présence du locuteur dans l'énonciation, elle a même des instruments spécifiques qui l'expriment ou l'impliquent, les motes oui et non assertant positivement ou négativement une proposition» (BENveniste, «L'appareil formel de l'énonciation», pág. 84).
} 
recurrir a la escritura para defender la propia identidad y prestigio ante la opinión pública.

En los acontecimientos de Madrid de mayo 1808, a la llegada de los imperiales, en los sitios de Zaragoza y en otros acontecimientos fundamentales de aquellos años, Mor se describe intensamente comprometido en la lucha contra los soldados napoleónicos. Sin embargo, su actividad no fue de verdadera participación en empresas militares. Su compromiso y su pasión reflejan el ideal del hombre de letras que prefiere utilizar la pluma y el razonamiento más bien que la espada. Es significativo el relato de su actividad de periodista (fundó en Valencia El patriota y dirigió también la Gaceta de Madrid), de consejero y estratega militar (aunque sus propuestas nunca fueron realizadas) y de su disponibilidad para adaptarse a diferentes ocupaciones: atalayó a los franceses desde la Torre Nueva durante el sitio de Zaragoza; fue a observar el despliegue de las fuerzas enemigas en la frontera catalana con Francia; y, antes de que el general Soult volviera a conquistar Madrid, aceptó el nombramiento de director de «los ramos de Ingenieros y de Artillería y del Depósito hidrográfico de Marina» (pág. 74).

Todo el Bosquejillo, pero especialmente la parte dedicada a la Guerra de la Independencia, presenta a su autor en incesante movimiento: es sorprendente su capacidad de desplazamiento, de viajar con soltura pese a lo avanzado de su edad y de encontrarse en un espacio de tiempo muy breve en varias ciudades diferentes ${ }^{24}$.

A causa de esta intensa actividad, se siente claramente comprometido frente a los franceses: «Últimamente yo no había publicado más que un himno para las tropas de Aragón, pero mis opiniones y mi conducta en Zaragoza, y aún en Madrid, eran bien notorias, y así mi temeridad en permanecer, teniendo mil proporciones para irme a Andalucía, fue casi increíble» (pág. 71). Luego, al regreso del rey, el autor se siente molesto en el Madrid de la restauración de Fernando VII, por su espíritu liberal y por haber compuesto un himno a la Constitución (La Constitución):

Es de advertir que en estos escritos, como en todos los míos, puse siempre de manifiesto mi entrañable, y estoy por decir innato, liberalismo, tan ajeno de

24 «Nuestro autor no podía estar quieto mucho tiempo en alguna parte [...] Puntualizar todas las vueltas, revueltas, lances y travesuras de nuestro autor es cosa asaz dificultosa. Difícilmente habrá en nuestra literatura libro que, siendo tan corto, tan sucinto, contenga tal cúmulo de pormenores e incidentes» (AzoRín, "Mor de Fuentes», págs. 67, 73). También Gil Novales subraya esta característica de Mor: «el múltiple Mor de Fuentes [...] está en todas partes [...] toda su vida es una continua sucesión de arranques: atrás la escolástica, delante el romanticismo, en ese espacio se mueve Mor libérrimamente, ejerciendo su gran curiosidad y su dote de fácil conversador [...] Tiene una obsesión de sensacionalidad, de vivir momentos históricos» (A. GIL NovALES, «El múltiple Mor de Fuentes», en La pequeñas Atlántidas, Barcelona, Seix Barral, 1959, págs. 107-108). 
todo rendimiento, como de los disparos torpes o maliciosos de los descerrajados. Con esta conducta conseguí, como lo tenía previsto, indisponerme con entrambos partidos, y así, a los asomos de la persecución, calculé que no habiendo lo que se suponía cuerpo de delito contra mí, en apartándome de la vista no irían a pesquisarme por los rincones de Aragón, como sucedió, en efecto (pág. 77).

Varios estudios aquí mencionados sobre el Bosquejillo subrayan los desacuerdos entre los documentos históricos y la narración de Mor, y lamentan la falta de coherencia, objetividad, plenitud y sobre todo verosimilitud. Alvar, en la introducción al Bosquejillo, afirma que el relato de Mor sobre su vida está lleno de lagunas e intermitencias: «quedan a veces los hechos menudos, se pierden los hondamente significativos» ${ }^{25}$. Mor cuenta que cuando todavía pertenecía a la Armada como Ingeniero Extraordinario se encontró embarcado en la fragata Juno que formaba parte de una escuadra que combatió en el litoral francés en 1794, durante la guerra con Francia, ofreciendo una breve relación de la expedición y de la escaramuza: «el Comandante Ezeta quiso absolutamente atacar a los enemigos, quienes [...] nos huyeron vergonzosamente. Fuimos aclamados por nuestra línea, bajamos dos oficiales a tierra y tuve el gusto de abrazar a mis íntimos amigos, los oficiales de guardias españolas» (pág. 51). Cáseda dice que en el Libro de Tripulación de la fragata Juno «no hay relación alguna acerca de sus intervenciones [las de Mor], ni informes secretos sobre el comportamiento demostrado en la batalla. Los textos impresos por protagonistas o testigos presenciales tampoco son muy generosos dando noticia del joven ingeniero» ${ }^{26}$. Mor asegura que una de sus acciones más útiles durante el sitio de Zaragoza fue la actividad de atalaya que desarrolló con gran determinación: «Ocurrióme aquel mismo día, 11 de junio, subir a la Torre Nueva para observar a los enemigos [...] atalayaba a mi satisfacción al enemigo, y así en mis partes solía especificar el número cabal de tropa, y calibre y la calidad de las piezas que se ponían en movimiento para sus ataques o expediciones» (págs. 67-68). Cáseda afirma que en ninguno de los informes de Mariano de Pano, que estudió con detalle muchos episodios de la defensa de Zaragoza, incluso los de la Torre Nueva, aparece ninguna noticia de Mor y su intervención en ella ${ }^{27}$. El escritor sigue su narración de la siguiente manera: «asomó un oficial de Marina que quiso encargarse de la comandancia de la atalaya, con lo cual pude complacer al general [el Capitán General Palafox] en ir absolutamente solo a reconocer el estado de nuestra raya con Francia por la parte confinante a Cataluña, de donde no se tenía en Zaragoza la menor

\footnotetext{
${ }^{25}$ Alvar, «Introducción», pág. 18.

${ }^{26}$ Cáseda, Vida y obra de José Mor de Fuentes, pág. 77.

${ }^{27}$ Ibíd., pág. 219.
} 
noticia» (pág. 69). A pesar de estas explícitas afirmaciones, Gil sostiene que Mor «nos dice que fue enviado por el general a recorrer el terreno por la raya de Cataluña, pero él mismo deja ver que no rindió informe alguno de su misión. Es decir que ni siquiera tenía que presentarse ante el general. Tan absurdo resulta que se impone la opinión de que dejó la ciudad, en pleno sitio, no por órdenes militares, sino por su propia decisión» ${ }^{28}$. Cáseda confirma las palabras de Gil y precisa que «entre el abundante número de relaciones de servicios que, tras la guerra, hace Palafox no hay ninguna del autor del Bosquejillo» ${ }^{29}$. Alvar, además, pone de relieve que «en la puntual Historia de los dos sitios [Madrid, 1831], Agustín Alcaide Ibieca no cita, a lo largo de tres tomos muy minuciosos, ni una sola vez a Mor de Fuentes, a pesar de hablar — también- de gentes que fueron a levantar en armas a las plazas del Pirineo. Tampoco hay mención de él en el circunstanciado Diario de Casamayor» ${ }^{30}$. Además, Gil y Pageard rehusan considerar el éxito y el significado que el poeta aragonés confiere a su viaje a París afirmando que "Mor demeure en marge de la société bourgeoise de Paris en raison de son impécuniosité; il demeure en marge de la société littéraire, jeune et bohême, en raison de son âge et de son caractère; il se trouve isolé» ${ }^{31}$. Quintana Pareja expresa un juicio muy parecido y propone una comparación entre su obra y la novela picaresca: «[el Bosquejillo]. Es la crónica supuesta de una vida de éxito y pretende ser un monumento al self-made-man. Lo que sucede es que termina siendo la crónica de un estrepitoso fracaso narrada, sin embargo, en la forma de un texto autobiográfico al uso, un fracaso general que incluye vida y también literatura. En este sentido, yo encuentro el referente más afín a la autobiografía de Mor en la novela picaresca» ${ }^{32}$. En la misma línea, Caballé pone en entredicho sus palabras: «Como siempre nuestro escritor se queda en el umbral del juicio explícito, tal vez a causa de su actitud de observador móvil de los acontecimientos relacionados con la invasión de los franceses: no colaboró con ellos, pero tampoco se comprometió con las fuerzas fieles a Fernando VII» ${ }^{33}$.

En fin, hay varios estudios que ponen en evidencia una falta de correspondencia entre el relato de Mor y los documentos de archivo, mencionando

${ }^{28}$ I. M. GIL, «Vida de José Mor de Fuentes», en Universidad, núm. 37, 1960, pág. 507.

${ }^{29}$ Cáseda, Vida y obra de José Mor de Fuentes, pág. 223.

30 Alvar, «Introducción», pág. 20.

${ }^{31}$ I. M. Gil y R. Pageard, «Mor de Fuentes et la France», en Revue de Litterature Comparée, núm. 35, 1961, pág. 369.

32 E. Quintana Pareja, «José Mor de Fuentes (1762-1848) y la escritura autobiográfica de su tiempo», en J. Romera Castillo (ed.), Escritura autobiográfica: Actas del II seminario internacional del Instituto de semiótica literaria y teatral, Madrid, Visor, 1993, pág. 337.

33 A. Caballé, «Memorias y autobiografía en España (siglos XIX y xx)», en Anthropos suplementos. La autobiografía y sus problemas teóricos, núm. 29, 1991, pág. 149. 
no sólo sucesos de la Guerra de la Independencia (aunque éstos son, sin duda, los más significativos), sino también de diferentes aspectos de su vida: el periodismo, las solicitudes de plazas públicas como ingeniero, los pleitos contra su cuñada, varios episodios de su viaje a París, etc.

Este aspecto es muy interesante porque pone de relieve la particularidad de la escritura de Mor y el potencial creativo de la narración. El enunciador reivindica a sí mismo la pertinencia de acontecimientos públicos y, de esta manera, desvía de la dóxa por lo que se refiere a la selección e interpretación de los eventos. El discurso personal del autor manipula y deforma el discurso historiográfico que se convierte en discurso de frontera, híbrido y ambiguo ${ }^{34}$. Los hechos relatados por Mor son, por lo tanto, el resultado de una interpretación que constituye $s u$ historia, ni falsa ni verdadera, sino simplemente suya ${ }^{35}$. Además, ello demuestra que él escribe para conseguir un reconocimiento de su carrera de literato y de patriota también porque sabe, a la hora de empezar la redacción del Bosquejillo, de la ausencia de su nombre en documentos y crónicas oficiales de aquel entonces:

Cierto papel y obra ha salido últimamente a luz titulándose Historia de los sitios de Zaragoza [se refiere a la obra de Agustín Alcaide Ibieca ya mencionada arriba] cuyo resultado es nublar las glorias, aventar el prestigio que tan excelsas hazañas dilataron por el orbe; pero el heroísmo de mis zaragozanos, a pesar de los escritores que por malicias o torpeza vinieron al parecer a marchitarla, descollará con nuevos auges de esplendor y patriotismo hasta la consumación de los siglos (pág. 69).

La estrategia del escritor es buscar con constancia puntos de contacto entre la versión pública de los acontecimientos y sus vicisitudes particulares para atraer la confianza del lector y persuadirlo de su interpretación alternativa. Sin embargo, él expresa en varias ocasiones el deseo de decir la verdad y ser lo más objetivo posible $^{36}$ : «voy a rasguear, compendiosa e imparcialmente, mi biografía» (pág.

\footnotetext{
${ }^{34}$ Paul de Man sostiene que «la distinción entre ficción y autobiografía no es una polaridad o/o, sino que es indecidible» (P. DE MAN, «La autobiografía como desfiguración», pág. 114).

35 «La ilusión comienza, por otra parte, en el momento en que la narración le da sentido al acontecimiento, el cual mientras ocurrió, tal vez tenía muchos, tal vez ninguno. Esta postulación del sentido determina los hechos que se eligen, los detalles que se resaltan o se descartan, de acuerdo con la exigencia de la inteligibilidad preconcebida. Los olvidos, las lagunas y las deformaciones de la memoria se originan ahí: no son la consecuencia de una necesidad puramente material resultado del azar; por el contrario, provienen de una opción del escritor que quiere hacer prevalecer determinada versión revisada y corregida de su pasado, de su realidad personal» (G. GusDorf, «Condiciones y límites de la autobiografía», en Anthropos suplementos. La autobiografía y sus problemas teóricos, núm. 29, 1991, pág. 15).

${ }^{36}$ La mayor parte de los autores del siglo xvin se plantea el problema moral de la imparcialidad. Dice Gusdorf que en realidad este problema depende de la falta de conciencia de estos autores que «creen poder
} 
43). No obstante, un aspecto importante de la obra de Mor es la fuerza consciente con la que se pone de relieve su individualismo subversivo, antitético, con el cual intenta desbancar y reemplazar la versión oficial de los acontecimientos: no incluye un apéndice documental que confirme y matice las distintas etapas de su existencia y afirma que no corrige lo que escribe. En el Bosquejillo domina el punto de vista y la subjetividad consciente y afirmativa del autor que rehusa corroborar su relato con materiales históricos o testimonios y que ni siquiera intenta ser exhaustivo relatando su vida (quedan amplios fragmentos de su existencia sin relatar y fases obscuras), ni preciso en la narración de muchos episodios y tampoco se preocupa de la posibilidad de ser mal interpretado ${ }^{37}$. Mor no plantea el problema psicológico de la memoria, como hacen otros autores de autobiografías, y no tiene el afán de recordarlo todo. Olvida y recuerda (quiere olvidar y desea recordar): la memoria selecciona y él acepta su ritmo intermitente.

El discurso individual se relaciona a cada momento con el discurso historiográfico. Los nombres, los lugares y los episodios conocidos y reconocibles adquieren, por lo tanto, un significado especial: no representación de la realidad, no referente histórico, sino «efecto de realidad ${ }^{38}$. Mor, en el deseo de representar el evento histórico, acaba por significar no tanto que tal evento ha acaecido verdaderamente, como (y aquí está el rasgo característico de su escritura) que ha realmente acaecido sólo en cuanto él ha contribuido o asistido directamente a su desarollo. Él supedita, pues, el significado del haber acontecido del discurso historiográfico al significado del haber estado de su discurso subjetivo: ha estado (ha visto) y por lo tanto sabe. De este modo, recuperando la antigua tradición del historiador como testigo, manifiesta una idea de historia basada en el conocimiento perceptivo, desbaratando el concepto de historia como disciplina científica ${ }^{39}$. El acto de ver (estar presente y observar directamente) constituye el saber y la historia deja de ser mediata por un método para convertirse en inmediata ${ }^{40}$.

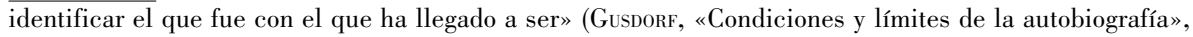
pág. 14).

37 «Gran parte de la identidad del autobiógrafo está ligada con la noción del «ser mal entendido», tanto por los antiguos amigos como por su audiencia inmediata» (E. Bruss, «Actos literarios», en Anthropos suplementos. La autobiografía y sus problemas teóricos, núm. 29, 1991, pág. 68). Preucupación difundida, pero que Mor no comparte.

${ }^{38}$ R. B ARTHES, «Le discours de l'histoire», en Le bruissement de la langue. Essais critiques IV, Paris, Seuil, 1984, pág. 165.

${ }^{39}$ J. Lozano, El discurso histórico, Madrid, Alianza Universidad, 1987, págs. 15 y ss.

${ }^{40}$ En contraposición con la idea moderna de historia como género que excluye toda forma lingüística autobiográfica (É. BEnveniste, «Les relations de temps dans le verbe français», en Problèmes de linguistique générale, Paris, Gallimard, 1966, pág. 239). 
En efecto, Mor afirma estar presente en todos los asuntos fundamentales de aquella época, coincidiendo con una tempestividad y una rapidez sorprendentes, con muchísimos personajes y acontecimientos que «hicieron la historia»:

La mañana siguiente, $1^{\circ}$ de mayo [...] hallándome yo en la Puerta del Sol, al asomar Murat todo aterciopelado y engalanado» (pág. 61); «Vino, en efecto, aquella noche Palafox; le vi la madrugada inmediata» (pág. 66); «mi plan era recoger todos los datos posibles acerca del estado de Madrid y sus inmediaciones para ir luego a incorporarme en su Estado Mayor, y entrar, si era dable, triunfante en la capital» (pág. 71). «Se me antojó ir en busca de Blake [...] para proponerle el marchar sobre Teruel ejecutivamente y cortar la retirada a los enemigos, rescatando así de un golpe a todo el reino de Aragón [el general Blake] me recibió con sumo agrado, celebró en gran manera mi pensamiento, pero me manifestó que [...] por ningún título podía desamparar aquellos puntos (pág. 73).

Cuando el ejército de Wellington conquista Madrid, Mor cuenta: «entré en Madrid casi al mismo tiempo que los ingleses» (pág. 74). El poeta aragonés se incorpora al relato muchas veces como amigo de personajes famosos o conversando con ellos amistosamente. Ya en las primeras páginas escribe:

el célebre conde de Peñaflorida, sujeto instruido y sencillísimo, y sobre todo dignísimo patricio (pág. 45); el célebre conde de Floridablanca, hombre en extremo superficial y aun ignorante, pero despejado, agasajador y, sobre todo, desinteresadísimo (pág. 46); En Cartagena, que fue mi departamento [...] entablé intimidad con los famosos Císcares que, como instruidos, eran de conversación amenísima y solían ser mis compañeros de paseo (pág. 46); En una de mis mansiones traté particularmente al famoso don Teodoro Reding, el héroe de Bailén (pág. 51); un destacamento de voluntarios de Aragón, que milagrosamente se apareció aquellos días a las órdenes de mi íntimo amigo y bizarrísimo oficial don Pedro Gasca (pág. 67); sabía yo que el ejército de Extremadura se iba organizando con grandísimos aumentos a las órdenes del general Cuesta, a quien había tratado íntimamente en Santander (pág. 71).

La coincidencia con hechos y personajes importantes brinda una visión particular de la identidad de Mor: esparcida en la historia oficial, triturada en un sinfín de acontecimientos. La capacidad de intuir el lugar y el momento más dignos de memoria representa una de las características más peculiares de su narración. Mor es gracias a tales coincidencias que comprueban y confirman su presencia, y por lo tanto su identidad. Él se reconoce sólo a través de los 
personajes o de los lugares históricos famosos ${ }^{41}$. Necesita verse y describirse hablando con Palafox o Godoy, escribiendo contra Napoleón y criticando a Moratín y a Hugo para poder reconocerse en la actualidad de su condición. El poeta aragonés, por lo tanto, no se representa sólo en función de un pasado vivido, sino también en función de un reconocimiento presente y un posible proyecto futuro.

La representación de esta coincidencia entre la vida del autor y los eventos que han recibido un estatuto histórico tiene como consecuencia la puesta en escena de una revancha y un rescate moral que él consigue con respecto a la sociedad literaria y científica de su tiempo que nunca le había otorgado un reconocimiento oficial. Demuestra la utilidad y la importancia de sus escritos que expresan la personalidad de un hombre capaz y culto, poeta y políglota, científico y patriota, preparado para reservarse un sitio privilegiado en la sociedad de su tiempo. Si no tuvo éxito en el pasado, lo tiene ahora, a través de su testimonio y de la confianza que exhibe en sí mismo. Muchos episodios representan un éxito y una satisfacción evidentes. Iniciales derrotas se convierten en verdaderos triunfos como, por ejemplo, la frustración de la ambición de llegar a ser director del Canal de Aragón por la negativa del ministro y el arrepentimiento de éste tras muchos años:

principal objetivo era lograr la dirección del Canal de Aragón, que pretendí con todo ahínco. Fui al Escorial con una carta de encarecida recomendación del duque de Frías, se la presenté al ministro Ceballos, quien tuvo a bien ponerme a otro que fue preciso retirar al instante; y mucho después, en el año 21, hallándome con Ceballos en una tertulia en Madrid, se mostró abochornado de la preferencia que diera a su favorecido (pág. 59).

Mor en varios puntos de su obra cuenta que tenía preparado un plan militar para derrotar a los franceses. Durante la guerra nadie aceptó sus consejos, pero finalmente el ejército inglés ganó a los imperiales a través de una táctica que era justamente igual a la que el autor intentó en balde de proponer:

Es de advertir que en mis escritos siempre había opinado y repetido que nuestras fuerzas principales debían agolparse sobre el Ebro, tomando la espalda a los enemigos [...] si perdemos la batalla en aquel punto nos venimos a quedar

${ }^{41}$ Mor pretende confundir los acontecimientos personales (los que simplemente acontecen) con los eventos que han recibido un estatuto histórico y ya han sido relatados. Por consiguiente es importante no tanto la naturaleza de los eventos históricos, como su función en el discurso (P. Ricoevr, Temps et Récit I, Paris, Seuil, 1983, págs. 161 y ss). 
como estábamos antes; si la ganamos, queda de un solo golpe rescatada la nación entera. Riéronse a carcajada los presumidos de mi propuesta, calificándola de rematado desvarío. En esto vi una mañana [...] al gobernador [...] y me anunció la victoria de los Arapiles [...] con aquel triunfo a la espalda, como había opinado siempre (págs. 73-74).

Otro tipo de vaticino puntualmente acertado es el siguiente: «Por la noche dije a los amigos que a la madrugada se perdería el Retiro por su dilatada, débil e indefensa cerca, como sucedió igualmente» (pág. 70). El autor alude a varios triunfos pequeños o grandes que nadie reconoció y de los que nadie habló como, por ejemplo, la liberación (conseguida junto a un amigo) de otro amigo prisionero de los napoleónicos, gracias a su atrevimiento y conocimiento del francés: «Trepando por entre la tropa de todas armas y las piezas de artillería a duras penas, hablamos en francés con el comandante, logramos nuestro intento, y nos trajimos en triunfo al rescatado» (pág. 63). Importante es el éxito obtenido en una reunión de la Sociedad Libre de Nobles Artes de París, donde leyó en francés una oda de su composición: «En seguida empecé, seguí y concluí mi recitado con toda la extensión de mi voz, nada escasa [...] Apenas dije el último verso se disparó un aplauso tan extraordinario [...] ya me había sentado cuando todavía duraba el palmoteo» (pág. 97).

El episodio que mejor demuestra este deseo de revancha es su encuentro con Godoy en París. El escritor aragonés encuentra dos veces, por casualidad, al hombre político español desterrado en Francia por «afrancesado». En este episodio es el mismo Godoy quien se interesa por Mor, porque conoce al aragonés a través de sus obras, mientras que el escritor ni siquiera reconoce a su interlocutor:

Me preguntó Esmenard: - ¿No conoció usted a aquel que venía conmigo ayer tarde? —No por cierto, le contesté; sería algún general francés. —iQué general, ni calabaza; si era Godoy! [...] Pasados tres o cuatro días me encuentro con el susodicho [Godoy]; se para, me sonríe y me dice: — [...] Ya dije la otra tarde a Esmenard que le conocía a usted mucho. - No sé como puede ser eso, le repliqué encogiéndome de hombros, porque yo no iba por allá. - Aunque la persona no venía, me dijo (con halagüieña sonrisa), me llegaban los escritos—. Y siguió en estos términos, casi requebrándome como a una Dulcinea (págs. 106-107).

El sujeto se superpone a la historia y restablece justicia. Godoy, que fue uno de los hombres más poderosos e influyentes de España, aparece supeditado con respecto a la dignidad de un hombre de letras que criticó con fuerza al jefe 
político sin comprometerse nunca con su gobierno ${ }^{42}$. En este fragmento Godoy devuelve simbólicamente a Mor su fama y su gloria.

\section{La simultaneidad}

Uno de los rasgos más característico del Bosquejillo es su escritura rápida, brillante y sobre todo fragmentaria ${ }^{43}$. Mor insiste mucho en su capacidad de improvisación y de escribir «sin borrador y sin retoques» (pág. 85), una técnica de escritura que no vuelve a lo ya escrito, que no necesita testimonios y en que la primera impresión es fundamental para emitir juicios y afirmaciones. No es lícito establecer hasta qué punto Mor no corrige lo que escribe. Sin duda el efecto que causa es el de una escritura inmediata, casi improvisada, de movimiento muy libre, que no tiene el fin de completar la narración de los relatos o seguir el orden cronológico. No sabemos hasta que punto todo ello es una técnica premeditada, pero es posible entender las palabras de elogio que empleó Azorín en definir «moderna» este tipo de escritura.

Los acontecimientos de una vida se presentan ante los ojos del autobiógrafo no según la secuencia cronológica tradicional, sino en círculo, al mismo tiempo, de manera sincrónica ${ }^{44}$. Mor realiza una narración fragmentaria, abundante de analepsis y prolepsis, en que se manifiesta confusión cronológica y simultaneidad de los acontecimientos evocados, alusión a acontecimientos futuros, narraciones por temas, saltos narrativos de varios años sin ninguna justificación, total libertad en el tratamiento del tiempo, complaciendo el curso fragmentario y flotante de la memoria ${ }^{45}$. Relatando, por ejemplo, como parte de la autobiografía su estancia en París y describiendo durante muchas páginas las maravillas de la ciudad desde el punto de vista social, literario, científico,

${ }^{42}$ Dice Gil Novales que para Mor «el que aduló a Godoy o a los franceses desde la usurpación de Murat, no es meramente un egoísta, sino un verdadero criminal» (A. GIL Novales, «El Patriota de Mor de Fuentes. Primera etapa (1812)», en Spagna Contemporanea, núm. 8, 1995, pág. 7)

${ }^{43}$ También Alvar subraya el «desaliño y la rapidez con que Mor escribe sus obras [...] Siempre el ritmo acelerado de la producción, sin detenerse demasiado en la fugacidad de cada instante» (Alvar, "Introducción», pág. 35).

${ }^{44}$ El autobiógrafo cuando escribe no hace sino juntar los añicos más importantes de su memoria seleccionadora, desligados ya de la fuerza de atracción del tiempo cronológico. No es una cuestión de fechas, porque hay que recuperar el tiempo perdido no «al pie de la letra», sino como si hubiera ocurrido (Demetrio, Raccontarsi. L'autobiografía come cura di sé, pág. 80).

45 «la présence, dans la narration historique, de signes explicites d'énonciation viserait à «déchronologiser» le «fil» historique et à restituer, ne serait-ce qu'à titre de réminiscence ou de nostalgie, un temps complexe, paramétrique, nullement linéaire, dont l'espace profond rappellerait le temps mytique des anciennes cosmogonies, lié lui aussi par essence à la parole du poète ou du devin» (BARTHEs, «Le discours de l'histoire», págs. 156-157). 
artístico y arquitectónico, el escritor anula el tiempo cronológico de su vida pasada, proyectándolo en un conjunto de escenas sincrónicas. La descripción de la vida cultural y de las bellezas artísticas de París, salpicadas por sus éxitos literarios, no necesitan, efectivamente, ningún tipo de secuencia. Además, inserta diferentes referencias metatextuales ${ }^{46}$ delatando, ya desde las primeras páginas, su actitud sobre la manera de redactar: «Antes de pasar adelante hay que recoger especies, tal vez omitidas arriba por el afán de abreviar mi narración» (pág. 50). Y más adelante aparece la siguiente confesión: «La dejé casi concluida [su obra Faustino y Dorotea] escribiéndola, según mi ya inveterada costumbre, sin borrador y sin retoques, como van estos apuntes. A este propósito se me trascordó expresar en su lugar debido que tenía compuesta otra novela, parte en historia y parte en cartas intitulada El Valero» (pág. 85); y poco después: «Mal haya el afán de estrechar mi narrativa, que me traspone recuerdos apreciables» (pág. 94). No inserta la parte olvidada en el lugar cronológica o temáticamente más idóneo, sino que la escribe desplazada creando la ilusión de la improvisación. Los fragmentos de relato se superponen provocando un efecto temporal no lineal, sino simultáneo.

En la elusión del tiempo cronológico y en la falta de un hilo conductor Mor pone de relieve su tiempo presente y su condición en el momento de la escritura. Él intuye que una autobiografía no es sólo un relato del pasado, sino también del presente y del futuro ${ }^{47}$, y sus olvidos, sus aparentes descuidos, su falta de exactitud y de precisión histórica, demuestran que no le importa definir, completar o establecer los acontecimientos de su vida pasada, sino interpretarse a sí mismo según su punto de vista en el momento de la redacción, para colocarse en un contexto social presente ${ }^{48}$. A este respecto es significativo que Mor concluya su autobiografía anunciando sus próximas publicaciones: «Quiero ahora manifestar a mis favorecedores, que entre el sinnúmero de proyectazos literarios que me están danzando en el magín, traigo un comedión inmenso, intitulado El romantismo, con decoraciones peregrinas, figurando alcázares sobrehumanos» (pág. 121); y, en la última página, termina así el relato de su vida:

\footnotetext{
${ }^{46}$ Barthes afirma que las referencias metatextuales provocan un roce entre el tiempo de la escritura y él de la materia enunciada (ibíd., pág. 155).

${ }^{47}$ La mémoire [...] n'est pas essentiellement tournée vers le passé, vers un présent passé qui aurait réellement et antérieurement existé. Elle séjourne pour les «garder», auprès de traces, mais de traces d'un passé qui n’a jamais été présent, de traces qui elles-mêmes ne se tiennent jamais dans la forme de la présence et restent toujours, en quelque sorte, à venir, vennues de l'avenir, venue du futur. La résurrection [...] ne ressuscite pas un passé qui aura été présent, elle engage l'avenir» (J. Derrida, Memoires pour Paul de Man, Paris, Galilee, 1988, pág. 70).

48 El único tiempo del «yo» es el tiempo de la escritura (C. Fernández Prieto, «La verdad de la autobiografía», en Revista de Occidente, núm. 154, 1994, pág. 127).
} 
En cuanto a empresas concluidas o proyectadas o principiadas, se pueden contar una traducción de todo el Salustio. Un curso de Literatura Castellana, esto es, Gramática, Retórica y Prosodia, por un rumbo absolutamente nuevo. La Historia Crítica de la Literatura Castellana desde su origen hasta nuestros días; y es mi ánimo escribirla sin abrir un libro, esto es, absolutamente de memoria. En cuanto a poesías sueltas $[\ldots]$ tengo en mi poder un número suficiente para formar una colección considerable [...] Se está imprimiendo la Poética, poema en doce cantos (pág. 138).

Otro fragmento importante que proyecta la autobiografía hacia el porvenir es aquél en que, deseando favorecer a un español encontrado en Versalles, lo recomienda a todos los lectores, presentes y futuros: «recomiendo entrañablemente a todos los españoles, habidos y por haber, la persona y familia de José Aguirre, frutero, que vive en una esquina al norte y no lejos del Palacio Real» (pág. 130).

La autobiografía, en efecto, se escribe también para aquella parte de tiempo entre el acto de la redacción autobiográfica y la muerte del autobiógrafo, el texto del autor no sirve para terminar el relato de una vida, sino para empezar $\operatorname{algo}^{49}$.

\section{Conclusiones}

La imagen del autor que se desprende del Bosquejillo es la de un hombre múltiple y contradictorio, lleno de entusiasmo y pasión, fiel a sus principios liberales, nunca interesado en un éxito fácil pero siempre comprometido con los diferentes conflictos que la historia de su época le ofrece. En esa forma fragmentaria de relatar manifiesta todas las contradicciones de su poliédrica personalidad y de su rica biografía. De ahí las palabras de Azorín, que vislumbró en el texto de Mor una anticipación de la literatura del siglo xx.

Su discurso autobiográfico adquiere valor en cuanto alegoría ennoblecedora del autor. El relato fragmentado y sincrónico desplaza la atención del lector hacia el tiempo presente de la redacción y pone de relieve las exigencias del autor en el momento de la escritura. Frente a una sociedad en la que nunca tuvo un verdadero y constante éxito, él obtiene una revancha moral escribiendo una auto-

\footnotetext{
${ }^{49}$ Dice Cerruti que en las autobiografías como en toda historia a final feliz, el héroe no muere, sino que sobrevive, aunque por pocos instantes, tras apoyar la pluma (T. Cerruti, «L'antico patto», en Sigma, XVII, núms. 1-2, 1984, pág. 129). Véase también: A. B Aтtistini, Lo specchio di Dedalo, Bologna, Il Mulino, 1990, pág. 134 y Demetrio, Raccontarsi. L'autobiografía come cura di sé, pág. 69.
} 
biografía no para descubrir quién es, sino porque tiene la necesidad de reescribir la historia para que se convierta en $s u$ historia. Eligiendo un punto de vista que mezcla lo personal y lo oficial, la verdad establecida y la memoria incompleta, contamina el discurso histórico con el discurso personal diluyendo el sujeto en un relato ambiguo y sin verdades inamovibles, a pesar de los nombres y episodios famosos mencionados. Las coincidencias se convierten en metáfora de este espacio indecidible entre lo oficial y lo personal, el objeto y el sujeto, lo ajeno y lo proprio, la verdad y la memoria. 